\title{
FORMAÇÃO CONTINUADA DE PROFESSORES DE EDUCAÇÃO FÍSICA NO PROGRAMA DE RESIDÊNCIA DOCENTE
}

\section{- FÁBIO JORGE DE SOUZA MOLINÁRIO}

https://orcid.org/0000-0003-3442-9043

Universidade Federal Fluminense

\section{DINAH VASCONCELLOS TERRA}

https://orcid.org/0000-0003-4589-3861

Universidade Federal Fluminense

A pesquisa tem como objetivo compreender o conhecimento profissional estabelecido entre professores experientes e iniciantes no Programa de Residência Docente (PRD) do Colégio Pedro II. As pesquisas apontam que o início da carreira apresenta dilemas e dificuldades para o professor iniciante, o mesmo encontra-se inseguro, ansioso e carregado por inúmeras informações que lhes são apresentadas na formação inicial. A literatura investigada destaca a necessidade de políticas que colaborem com essa entrada na carreira, na perspectiva de apoiar a permanência do professor no campo profissional, desse modo, para orientar nossa investigação, apostamos história oral temática, com entrevista e textualização no formato de narrativa. Estas revelam que um dos espaços propícios para a associação do conhecimento profissional aconteceu no reconhecimento do exercício do trabalho e nas circunstâncias vivenciadas nas distintas realidades, condições estruturais, sociais e econômicas. Estas ao serem dialogadas com professores experientes criam dispositivos de reflexão e análise colaborando para uma formação mais aprofundada.

Palavras-chave: Programa de Residência Docente. Formação de professores. Educação Física.

\section{ABSTRACT CONTINUING TRAINING OF PHYSICAL EDUCATION TEACHERS IN THE TEACHER RESIDENCE PROGRAM}

The research aims to understand professional knowledge established between experienced teachers and beginners in the Teaching Residency Program (PRD) of School Pedro II. Research shows that the beginning of the career presents dilemmas and difficulties for the 
beginning teacher, he is insecure, anxious and burdened by innumerable information that is presented to him in the initial formation. The investigated literature highlights the need for policies that collaborate with this career entry, in order to support the permanence of the teacher in the professional field, so, to guide our investigation, we bet on oral life history articulated with thematic oral history, with an interview. And actualization in narrative format. These reveal that one of the favorable spaces for the association of professional knowledge took place in the recognition of the exercise of work and in the circumstances experienced in the different realities, structural, social and economic conditions. When dialogued with experienced teachers, they create reflection and analysis devices, contributing to a deeper formation.

Keywords: Teaching Residence Program. Teacher Training. Physical Education.

\section{RESUMEN FORMACIÓN CONTINUA DE PROFESORES DE EDUCACIÓN FÍSICA EN EL PROGRAMA DE RESIDENCIA DE PROFESORES}

El objetivo de la investigación es comprender el conocimiento profesional establecido entre maestros experimentados y novatos en el Programa de Residencia Docente (PRD) de Colégio Pedro II. La investigación muestra que el comienzo de la carrera presenta dilemas y dificultades para el maestro principiante, que es inseguro, ansioso y cargado de innumerables informaciones que se le presentan en la formación inicial. La literatura investigada destaca la necesidad de políticas que colaboren con esta entrada en la carrera, con el fin de apoyar la permanencia del maestro en el campo profesional, por lo que, para guiar nuestra investigación, apostamos por la historia de la vida oral articulada con la historia oral temática, con una entrevista. y textualización en formato narrativo. Estos revelan que uno de los espacios favorables para la asociación del conocimiento profesional tuvo lugar en el reconocimiento del ejercicio del trabajo y en las circunstancias experimentadas en las diferentes realidades, condiciones estructurales, sociales y económicas. Cuando dialogan con profesores experimentados, crean dispositivos de reflexión y análisis, lo que contribuye a una formación más profunda.

Palabras Clave: Programa de Residencia Docente. Formación de Profesores. Educación Física. 


\section{Introdução}

A formação de professores e o trabalho docente são, sem dúvida, campos multifacetados e cercados de complexidades. Com os avanços dos estudos referentes aos dilemas enfrentados por professores iniciantes, as novas políticas e programas de acompanhamento e/ou tutoria docente vêm ganhando força no cenário internacional e ampliando seu espaço através de debates, reflexões e desenvolvimento de pesquisas (MARCELO e VAILLANT; 2012). Essa relevância pode ser explicada em razão de ser o início da carreira docente um momento importante na trajetória profissional, na obtenção e consolidação dos saberes e competência profissional e, em sua maioria, o período de maior solidão.

Para pensarmos a formação dos professores em início de carreira, e o modo como são recebidos e acolhidos nos futuros ambientes de trabalho, é preciso desenvolver estratégias que colaborem para superar as dificuldades enfrentadas no convívio com os alunos, no domínio e trato do conteúdo a ser apresentado, e na falta de apoio das instituições e da comunidade. Tais estratégias podem amenizar os impactos negativos abrandando, desse modo, a sensação de abandono e as tensões provocadas no início da carreira. Entretanto, algumas vezes, é preciso considerar que a questão necessita de ações mais efetivas como a criação, mesmo em caráter experimental, de programas específicos para os professores no início da carreira na perspectiva de ampliar a reflexão sobre o tema.

Considerando esse e outros contextos da formação de professores no ano de 2009, o Ministério da Educação (MEC) institui através do Decreto no 6.755 a Política Nacional de Formação de Profissionais do Magistério da Educação Básica, reforçando a Lei no 11.502/2007 que delega a Coordenação de Aperfeiçoamento de
Pessoal de Nivel Superior (Capes) o fomento de programas de formação inicial e continuada de professores. Nesse movimento, surgem diferentes programas de incentivo e valorização ao magistério para a formação inicial e continuada de professores da educação básica, como exemplo: Plano Nacional de Formação dos Professores da Educação Básica (Parfor); Programa Institucional de Bolsa de Iniciação à Docência (Pibid) e o Programa de Residência Docente (PRD), que é o foco de nossa pesquisa.

O PRD surge do diálogo iniciado em 2011 entre a Capes e o Colégio Pedro II a partir, também, da demanda apresentada na meta 16 do Plano Nacional Educação, que trata da temática de valorização da carreira docente e da formação de professor. Tal meta aponta para a necessidade de que $50 \%$ dos professores da educação básica tenham formação em nível de pós-graduação lato sensu até 2024, garantindo a todos(as) os(as) profissionais formação continuada em sua área de atuação, considerando as necessidades, demandas e contextualizações dos sistemas de ensino. A medida qualifica a formação continuada dos professores, potencializando suas trajetórias profissionais e amenizando os impactos referentes aos primeiros contatos com a sala de aula, os alunos e a escola.

Considerando o tema do início da carreira e projetos que buscam de alguma forma amenizar os dilemas nesse período, a pesquisa tem como objetivo analisar o PRD do Colégio Pedro II na organização e no desenvolvimento do conhecimento profissional estabelecido entre os professores supervisores e residentes docentes participantes do programa.

\section{O início da carreira docente}

Apoiar os professores iniciantes é prerrogativa constante para que os mesmos possam se desenvolver pessoalmente e profissionalmen- 
te, essa afirmativa, de certa forma, é consenso entre autores que discutem o início da carreira docente, o que leva ao reconhecimento das dificuldades que os novos professores encontram na transição de estudantes para mestres. Esse “[...] é um período de tensões e aprendizagens intensivas em contextos geralmente desconhecidos e durante o qual os professores iniciantes devem adquirir conhecimento profissional, além de conseguir manter um certo equilíbrio emocional" (MARCELO e VAILLANT, 2012, p. 49).

0 início da carreira é fundamental para o futuro profissional, pois é nesse período que se estrutura e se adquire os saberes e as práticas que fundamentam suas aulas, localizando o contexto do trabalho docente. Nessa dimensão, podemos compreender as três fases da iniciação à docência apresentada por Tardif (2002): a primeira, que antecede o início do ano letivo e as orientações destinadas aos professores, consolidam a passagem da condição de estudante para a de professor; a segunda fase é a iniciação à prática de ensino e a necessidade de transmissão do conhecimento; e a terceira retrata o período em que o professor descobre as reais características de seus alunos, fugindo daquele plano idealizado de alunos perfeitos, tranquilos e dispostos sempre às atividades propostas.

Nessa mesma linha argumentativa, Cavaco (1995, p. 162-163) assegura que:

O início da atividade profissional é, para todos os indivíduos, um período contraditório. Se, por um lado, o ter encontrado um lugar, um espaço na vida ativa, corresponde à confirmação da idade adulta, ao reconhecimento do valor da participação pessoal no universo do trabalho, à perspectiva da construção da autonomia, por outro, as estruturas ocupacionais raramente correspondem à identidade vocacional definida nos bancos da escola, ou através das diferentes atividades socioculturais, ou modelada pelas expectativas familiares.
Revisando a literatura correspondente à entrada de professores nas escolas, identificamos que uma boa recepção é condição essencial para o desenvolvimento de um trabalho potente e seguro nas instituições. O processo de socialização profissional pode contribuir com a constituição dos saberes da experiência e a relação entre os educadores, principalmente nos momentos dedicados ao planejamento coletivo que ajudam a fortalecer as práticas de ensino, mostrando que muitas das estratégias adotadas são aprendidas no contexto real de ofício docente.

No caminho da formação, Reali (2008, p. 79) afirma que "o processo de aprender a ensinar e se constituir enquanto um educador é contínuo e se desenvolve durante todo o período de trabalho", ressalta, porém, que as demandas de formação continuada para professores iniciantes e os mais experientes são diferenciadas; os recém-formados estão construindo seus saberes enquanto que os veteranos precisam rever conceitos, práticas e metodologias de ensino. A ideia é que a formação de professores seja pensada e desenvolvida como um processo, voltado para o desenvolvimento profissional levando-se em consideração as necessidades e especificidades de cada uma de suas distintas etapas (DAY, 2001).

Esse conjunto de informações evidencia que é indispensável repensarmos os programas de formação, rompendo com o pensamento linear e reducionista da realidade e do contexto social, esclarecendo aos iniciantes a complexidade da profissão e seus desafios, apoiando-os e potencializando suas ações para o enfrentamento da realidade. Mira (2015 apud Gatti 2012, p. s/p) destaca essa necessidade, afirmando que o professor iniciante

\footnotetext{
[...] se defronta com uma situação complexa que integra objetivos a atingir, formas de comunicação didática com crianças e jovens, emoções e reações, alunos heterogêneos, com suas
} 
características individuais e socioculturais, os conteúdos disciplinares que tem que manejar e ajustar a um nível escolar determinado, à idade dos estudantes, o clima psicosociológico da escola, entre outros aspectos que estão presentes nas relações na educação escolar.

É imprescindível propiciar uma formação que permita os professores trabalharem com as dificuldades encontradas no cotidiano escolar, o futuro professor deve ser apresentado e inserido à instituição que o abrigará durante sua trajetória profissional, deste modo, ele será capaz de compreender o contexto da escola ao qual se vinculará e obter a ajuda necessária ao desenvolvimento das atividades propostas ao longo de seu percurso profissional. É por meio desse cenário que buscamos compreender o PRD, por ser um programa que surge com o compromisso e o desafio de investir nos professores de até três anos de atuação da educação básica, a fim de investigar as querelas do percurso docente inicial e quais medidas podem ser tomadas para (com) esses profissionais que beneficiem e aprimorem suas atuações.

\section{O PRD do Colégio Pedro II}

O PRD é instituído com os objetivos de: a) validar o impacto da oferta de uma proposta inovadora para a formação continuada dos professores da rede pública de educação básica, a partir da experiência do estado e do município do Rio de Janeiro; b) oportunizar o compartilhamento, mediante imersão no cotidiano do Colégio Pedro II, a vivência educacional da instituição, oferecendo ao recém-licenciado uma formação complementar em questões de ensino e aprendizagem da área ou disciplina e em aspectos da vida escolar; c) propor aos professores da educação básica uma vivência profissional orientada que propiciará o acompanhamento de ações pedagógicas, o desen- volvimento da autonomia na produção e na aplicação de estratégias didáticas, a internalização de preceitos e normas éticas e o estímulo à reflexão crítica a respeito da ação docente; d) promover e fomentar a articulação do Colégio Pedro II com a rede pública de educação básica, estendendo a essa a tradição e a experiência do Colégio, contribuindo para elevar o Índice de Desenvolvimento da Educação Básica (Ideb) e o padrão de qualidade da educação básica no estado (BRASIL, 2011).

O programa teve início em 2012 como um projeto piloto e ao longo desses anos foi se expandindo pelos diversos campi do Pedro II, possibilitando, com sua dimensão, se tornar um projeto que se articula de diversas formas. O Pedro II, além de ser um colégio público com atuação na educação infantil, ensino fundamental e médio, em 25 de junho de 2012, foi equiparado aos Institutos Federais, tornandose uma instituição em condições de oferecer cursos de formação continuada para professores. É um projeto inovador e sua organização permite a construção de um espaço de formação em serviço, que atenda às necessidades de mudanças na formação continuada dos profissionais da educação básica. Esse novo formato é inspirador, por questionar os já tradicionais e limitados métodos de formação continuada.

\section{Aspectos metodológicos}

Adotamos como metodologia para essa pesquisa princípios da História Oral Temática (FONSECA, 2003) instigados pelos desafios que atravessam nossas práticas profissionais docente e por compreender a capacidade de nos dar pistas sobre o diálogo desempenhado pelos professores supervisores e residentes na articulação de suas experiências e necessidades pedagógicas no cotidiano escolar.

O ponto de partida para a construção da pesquisa em história oral são as entrevistas, 
que neste trabalho foram realizadas com professores da rede pública de ensino do Rio de Janeiro. Elegemos os entrevistados a partir de uma lista encontrada no site do colégio Pedro II, em que constava os nomes dos professores residentes e professores supervisores que participariam da residência do colégio em 2014. No entanto, ocorreu que, coincidentemente, identificamos na lista três colegas da graduação, o que nos facilitou o contato para o convite para realizar as entrevistas.

$\mathrm{Na}$ sequência, realizamos a textualização das entrevistas organizando-as num processo narrativo em que retiramos as perguntas para dar movimento nas disposições da história narrada por eles; por fim, fizemos nova devolução para reordenação e autorização das narrativas. A partir daí, dialogamos com os sujeitos criando outra narrativa que nos permitiu compreender o conhecimento profissional que eles estabeleceram, considerando o início de carreira. Justificamos que para este texto optamos por manter somente a análise dos pesquisadores e apresentar parte das narrativas dos colaboradores, divididos entre supervisores e residentes. São eles: Supervisores - Ivone Azevedo, professora da rede de ensino atuando há 22 anos no Colégio Pedro II e Fabiano Salles, professor com experiência na educação básica há 11 anos, dos quais oito foram no Colégio Pedro II; Residentes - Rafael Souza e Jonimar Santos, ambos com sete anos de experiência em atuação na rede municipal de ensino do Rio de Janeiro.

\section{Aprendendo com as experiências narradas}

O PRD possui uma organização que permite a construção de um espaço de articulação de formação em serviço, que atende às necessidades de mudanças na formação continuada dos profissionais da educação básica e incen- tiva a formação em nível de pós-graduação lato sensu. Esse novo formato é inspirador por questionar os já tradicionais e limitados métodos de formação continuada existentes em outras instituições de ensino superior apontado pela literatura, muitas vezes, como limitador por não garantir o diálogo com o cotidiano escolar dos professores.

No início do programa, estabeleceu-se com as redes públicas de ensino um acordo com as direções escolares para a liberação dos professores participantes, de modo que esses profissionais teriam a carga horaria reduzida em suas instituições de origem sem prejuízo financeiro. Ficou compreendido, naquele momento, que a medida facilitaria e estimularia a formação continuada desses docentes, no entanto, esse acordo não foi cumprido. Durante todo andamento do curso, os professores residentes demonstravam preocupação em conseguir cumprir as demandas, por não contar com liberação de suas instituições. No dia a dia, o que foi anteriormente combinado, não se consolidou e o que se viu no cotidiano escolar foram alguns diretores criando barreiras para liberar os professores, fazendo com que esse descumprimento gerasse desconforto e abandono de alguns residentes.

No início do programa, eram extensivas as horas de atividades estabelecidas pelo PRD - o que foi diminuindo ao longo do tempo e a falta de interação e comunicação entre o Colégio Pedro II e as escolas onde atuavam os residentes, acarretando assim, em inúmeras dificuldades de permanência no programa, fato que se constatou através das entrevistas realizadas para esta pesquisa.

O meu diretor era quem comprovava a ação, assinando os documentos e enviando-os ao Pedro II. Essa ação estabelecia a troca entre as instituições. Não tive grandes problemas quanto a isso, agora negociação de horários foi zero, sem condições de conseguir uma redução de horas. 
Quando se entra em alguma prefeitura e se está em estágio probatório, o professor se torna um refém dos diretores. Caso você peça uma redução de horário, mudança de dia ou licença, eles alegam que você está em estágio probatório ou que existe uma carência de professores na rede, dificultando qualquer formação ou iniciativa de formação continuada dos educadores. Essa relação com o diretor é bem complicada. Ele fazia corpo mole para assinar meus papéis, achando que eu iria pedir uma licença. (Narrativa do professor residente Rafael)

A partir de 2013, o PRD deixou de ser um Projeto Especial e passou a ser considerado um Programa de Formação Continuada voltado aos professores da educação básica. Foi nesse momento que o ingresso de professores residentes se deu pela primeira vez por meio de edital. A nova organização facilitou a divulgação entre os professores das redes estaduais e municipais com ampla divulgação no site do Colégio Pedro II, permitindo que os professores interessados procurassem diretamente a instituição, tirando das Secretarias de Educação a função de intermediar o desejo e a busca pela formação.

Considerando que era princípio do projeto o pré-requisito de que o professor estivesse atuando em sala de aula, e como foi identificado pelos narradores que o tempo era uma dificuldade para cumprir as horas destinadas, o programa reconheceu essa dificuldade e ajustou seus horários de demandas a partir das experiências anteriores. A negociação para liberação do trabalho ficou por conta da articulação entre a direção das escolas e os residentes, sabendo que o elo mais frágil nesse diálogo é o professor, esse tipo de sistema sufocou os residentes. Segundo Rafael:

[...] nós somos pequenos dentro desse sistema todo. Você imagina para um gestor como o Crivella, por exemplo, eu falar para ele: 'ai vamos deixar um ano esse professor na escola só para ele se adaptar e poder no futuro fazer um bom trabalho, ser um bom professor, querer ser professor e não desistir da carreira'. o gestor quer colocar esse cara para trabalhar o mais rápido possivel, ele está pagando esse professor, é uma relação muito cruel com o profissional. (Narrativa do professor Rafael)

A escola deveria ser o local e espaço de atuação e formação continuada em serviço dos professores, que além de produzir dinâmicas vinculadas à docência, poderiam refletir $e$ reorganizar quando necessário suas práticas pedagógicas. Em nossas pesquisas, encontramos um conjunto de trabalhos que legitimam a escola enquanto espaço de formação em serviço do professor (GARCIA, 1999; CANDAU, 1998). Os(as) autor(as) ressaltam que programas de formação devem reconhecer a escola enquanto local de produção de conhecimento capaz de reorganizar as necessidades de aprendizagem dos alunos e potencializar o trabalho pedagógico dos professores. E para Candau apud Inforsato et al. (2015):

[...] considerar a escola como lócus de formação continuada passa a ser uma afirmação fundamental na busca de superar o modelo clássico de formação continuada e construir uma nova perspectiva na área de formação continuada de professores. Mas este objetivo não se alcança de uma maneira espontânea, não é o simples fato de estar na escola e de desenvolver uma prática escolar concreta que garante a presença das condições mobilizadoras de um processo formativo. Uma prática repetitiva, uma prática mecânica não favorece esse processo. Para que ele se dê, é importante que essa prática seja uma prática reflexiva, uma prática capaz de identificar os problemas, de resolvê-los, e cada vez as pesquisas são mais confluentes, que seja uma prática coletiva, uma prática construída conjuntamente por grupos de professores ou por todo o corpo docente de uma determinada instituição escolar. (CANDAU, 1998, p. 57)

Nas narrativas, percebemos que o PRD oportuniza a socialização de experiências, muitas vezes, tão ausentes nas escolas de edu- 
cação básica, que nos pareceu indispensável manter ativo o diálogo entre as diferentes figuras que compõem a residência docente como parte fundamental para a qualidade dessa formação. O PRD, pela sua configuração e inserção nas redes e sistemas educacionais, ampliou seu potencial de transformar o modelo de formação continuada docente, ajudando os novos professores na construção de seus saberes e ações pedagógicas. Esse movimento, segundo Nóvoa, tem o potencial de proporcionar a implementação de uma cultura de formação que reconheça a importância dos saberes da experiência, pois, para o autor:

Não há respostas feitas para o conjunto de dilemas que os professores são chamados a resolver numa escola marcada pela diferença cultural e pelo conflito de valores. É importante assumir uma ética profissional que se constrói no diálogo com os outros colegas. A colegialidade, a partilha e as culturas colaborativas não se impõem por via administrativa ou por decisão superior. A formação de professores é essencial para consolidar parcerias no interior e no exterior do mundo profissional e para reforçar o trabalho cooperativo dos professores. (NÓVOA, 2012. p. 18)

Há no programa, em função da dinâmica narrada por Ivone, Fabiano, Jonimar e Rafael, a oportunidade de professores iniciantes retomarem os conhecimentos da formação inicial dialogando com as vivências da prática profissional. Acreditamos que, de forma diferente, os professores supervisores também retornam a essas reflexões, o que nos permite afirmar que a formação ocorre para todos. As narrativas revelam que o espaço propício para a associação dos saberes adquiridos na formação inicial com o contexto real da sala de aula aconteceu no reconhecimento de que é no exercício do seu trabalho e das circunstâncias impostas a ele que o professor residente se depara com distintas realidades, condições estruturais, sociais e econômicas que ao serem dialogadas com professores experientes criam dispositivos de reflexão e análise colaborando para uma formação teórico prática.

Essa reflexão nos permitiu inferir a relevância na formação inicial em inserir os licenciandos com e na escola nos primeiros anos do curso. Algumas iniciativas de projetos nesse sentido foram fomentadas a partir da organização de uma política de formação de professores nos governos Lula e Dilma do Partido dos Trabalhadores (PT), fortalecendo a ideia de uma formação em diálogo com a escola. Pesquisas sobre esses projetos destacam essa condição, como exemplo Nóvoa (1995), mas fazem duas ressalvas: a primeira é que os projetos não atingem a todos(as) licenciados(as); e a segunda diz respeito à inexistência do impacto dos projetos nos currículos dos cursos de formação de professores, que apresente essa inserção no campo de trabalho.

Analisando as narrativas sobre o modo como os professores supervisores conduziram suas orientações, identificamos que estes a organizaram em função das suas experiências e daquilo que dominam. A trajetória profissional de Ivone, por ser uma professora que gosta de estar em sala, da criação de material, do contato direto com os professores, aparece encarnada na narrativa de Jonimar e dos demais residentes sob sua orientação. Isso não determinou todos os trabalhos finais que foram apresentados, mas contribuiu para reflexão e organização pedagógica de determinados conteúdos, seja pela escassez de material e estrutura precária nas escolas dos residentes, e para associação de como alguns temas podem ser abordados desde outras perspectivas. A professora afirma que em algum momento do PRD começa um movimento de valorização do Produto Acadêmico Final (PAF), o que the parecia demasiado na exigência. Sua preocupação

1 Alguns desses projetos são: Pibid e Programa de Consolidação das Licenciaturas (Prodocência). 
voltava-se para um olhar mais humanizado da prática pedagógica, em que as experiências e os esforços dos residentes pudessem se organizar e experimentar a partir de um projeto de intervenção em suas escolas, que promovesse reflexão e crítica com mais reconhecimento. Ela afirma:

Uma de minhas residentes mexeu com a escola inteira dela, com seu planejamento procurando envolver os alunos, ela quase foi reprovada, eu tive que brigar por isso, eu disse para alguns colegas: 'como é que vocês propõem um curso, que a intenção dele é mudar a visão da escola?'. Minha residente consegue mobilizar a escola inteira com seu trabalho e vocês querem reprová-la? Não porque seu texto estava ruim, só não estava claro onde se encontrava a metodologia, tinha tudo lá, mas os avaliadores queriam tudo 'separadinho', metodologicamente organizado e padronizado. Eu tive que falar, é por conta disso que vocês vão reprovar todo um trabalho magnifico que ela fez? (Narrativa da professora supervisora Ivone)

As narrativas revelam, mesmo com as diferentes formas da dinâmica estabelecida entre supervisores e residentes, um ambiente de reflexão sobre o trabalho docente entre professores experientes e recém-formados, estabelecido pelo diálogo e trocas de conhecimentos e informações sobre o seu ofício e contexto escolar. Se a universidade tem o papel importante na formação dos professores, é inegável a tarefa da escola no incentivo aos processos de fortalecimento da profissão e da manutenção desses professores no campo de atuação. O Pedro II, por ser uma escola de educação básica, permitiu uma conversa entre os participantes na troca de saberes com e entre as escolas públicas de educação básica do Rio de Janeiro, dando pistas e referendando princípios para formação inicial, como destacados nas narrativas. Essa ação permite a criação de redes de apoio entre os professores participantes do programa.
Tornar-se um professor melhor é um processo. É compreender e interpretar as coisas do mundo. É estar mais atento e crítico ao que nos rodeia. É perceber coisas que não eram tão claras antes da leitura de um texto, da discussão em uma oficina ou no mero diálogo informal com os pares. Essa visão me permitiu articular o que era feito no Pedro II com a minha realidade escolar. (Narrativa do professor residente Rafael)

Os professores residentes salientam, como pontos positivos da residência docente, o apoio entre os participantes do programa, a possibilidade de se reconhecer enquanto um educador e a qualidade que suas aulas passam a ter a partir do que é observado e dialogado no percurso da experiência. A impressão é de que os professores chegam ao PRD desejando a formação continuada por necessitarem do contato com seus pares, visando trocas de experiências. Foi possível notar nas narrativas dos residentes a falta de apoio de seus pares na escola no início da docência:

Minha relação com os professores de educação fisica que já estavam nessa escola foi quase nula, tínhamos horários diferentes, dialogávamos muito pouco, e o pouco que a gente dialogava, eu não sentia ressonância na minha fala. Eu era um professor novo, carregado de angustias e inquietações sobre a minha profissão. Trabalho com duas autoras, Marilyn Cochran-Smith e Susan Lytle, que defendem que o trabalho do professor é muito privado, é um trabalho isolado, e em Caxias eu encontrei esse isolamento. Eu trabalhava sozinho, eu podia fazer o que eu quisesse, inclusive 'rolar bola'. (Narrativa do professor Fabiano)

Em seus estudos, Mariano (2006) indica que a solidão e o isolamento são sentimentos que atingem os professores iniciantes. Essas emoções se justificam na ausência de trabalhos coletivos nas escolas e na inocência e insegurança do professor ao iniciar a docência. As narrativas e outros estudos mostram que essa dificuldade está centrada, algumas vezes, no processo de organização do sistema edu- 
cacional na contratação de professores. Temos professores, principalmente os especialistas, de contrato de 20 horas semanais que comparecem na escola duas e/ou três vezes na semana e professor 40 horas semanais que vão todos os dias. Essa disparidade causa desencontros na escola para planejamento e nas reuniões pedagógicas, visto que professores possuem mais de um cargo, às vezes, em redes de ensino diferentes, para complementarem seu salário. Essa condição é reconhecida por todos os sujeitos, ao compararem as realidades escolares, nesse caso, o Pedro II, em que os professores cumprem 40 horas dedicação exclusiva.

Certa vez o conselho caiu em um dia que impossibilitou a presença do outro professor de educação fisica, eu não tive a oportunidade de conversar com ele sobre o desempenho dos alunos. Tive que decidir a vida dos alunos na disciplina, sem debater com meu colega, que ministrou as aulas durante o ano e deu as notas para eles. (Narrativa do professor residente Rafael)

O conhecimento sobre o funcionamento do Pedro II foi também refletido por Jonimar e Rafael. Jonimar traz diversas vezes em sua narrativa essa preocupação, refletindo as dificuldades da escola em que atuava. Destacamos como importante, porque também vivemos esse processo como professores nos primeiros contatos com a escola, o quanto as orientações sobre o funcionamento destas são necessárias para os professores que chegam nas instituições. Para Nono (2011, p. 166), “o ambiente organizacional influencia a carreira por meio de estilos de gestão encontrados". Em outro caso, Rafael nos apresenta um professor que teve seu salário não pago por ter assinado a folha de ponto de forma errada. A ação e sua consequência produziram um professor insatisfeito e desmotivado.

Por outro lado, houve um cuidado por parte dos supervisores para os deslumbramentos dos residentes que entravam no Pedro II, isso diz respeito à organização e à estrutura do colégio. Fabiano aponta que havia sempre uma preocupação de sua parte em passar a mensagem de que o Colégio Pedro II não é um modelo pronto, único e padrão em referência na educação, que deveria ser copiado e colado em suas práticas nas escolas de origem. Havia um cuidado em conduzir esse deslumbre com a escola, principalmente no início. Fabiano e Ivone se preocupavam para que os residentes compreendessem, ainda que atravessados pelas experiências do colégio, que deveriam criar suas próprias identidades, adaptando aquilo que construíam na residência às suas realidades.

O programa permite que o professor recém-formado estabeleça uma relação de orientação com professores experientes do Pedro II. Essa conexão carrega em si uma formação continuada para ambos os participantes, já que durante o processo se estabelece interação entre os profissionais. As referências nos apontam que esse tipo de iniciativa é relevante e capaz de desenvolver, principalmente nos professores iniciantes, autonomia e reflexão crítica sobre suas ações, podendo gerar mais qualidade ao exercício da docência, pois,

É no contexto escolar que o professor iniciante irá procurar superar suas dificuldades, elaborando, em conjunto com outros profissionais da escola, um projeto de formação em serviço que $o$ ajude a transpor suas dificuldades [...]. É o próprio professor que saberá quais são as suas dificuldades e, já no início da carreira, ele deverá se apropriar de seu projeto de formação, o que terá a supervisão do professor coordenador pedagógico, ajudando-o a vislumbrar as carências do momento. (FRANCO, 2000 apud GIORDAN e HOBOLD, 2016, p. 9)

Por meio da dinâmica desenvolvida por Ivone com Jonimar, e Fabiano com Rafael, estes conseguiram vivenciar realidades, contextos e problemas com algumas semelhanças, mas 
também tiveram a possibilidade de se contrapor aos seus contextos, confrontando-se com distintas possibilidades e diálogo com as formações recebidas, seja inicial ou continuada. Rafael já tinha realizado outro curso de especialização na mesma instituição da formação inicial e pôde compreender as diferenças nos processos formativos. Levando em consideração o fato de que a narrativa do Rafael deu-se após três anos da conclusão no PRD, posteriormente, vindo a concluir o mestrado na mesma instituição de ensino, o Pedro II, e em seguida, alcançando aprovação no concurso público da prefeitura do Rio de Janeiro para atuar em uma rede de ensino maior, em que assumiu em estágio probatório a função de coordenador pedagógico dessa escola, percebemos que os atravessamentos que sua narrativa revelam de outros espaços promovem a ampliação de seus questionamentos.

A qualidade de um bom programa de indução à docência é perpassada pelo entendimento de Ivone e Fabiano sobre a sua importância no trato com os iniciantes. Eles forneceram apoio emocional, orientaram questões curriculares, didáticas e disponibilizaram informações internas sobre as normas e procedimentos na escola. Encontros frequentes entre os professores é fundamental para que essa relação se estabeleça e os conhecimentos sejam compartilhados.

Os problemas, demandas, questões e inquietações que Rafael e Jonimar trouxeram para o diálogo com Fabiano, Ivone e seus colegas não eram da prática pedagógica, eram de uma ordem estrutural, burocrática e social. os residentes buscavam por uma formação para dar respostas aos fatos concretos que atravessavam sua rotina na escola. Rafael e Jonimar em nenhum momento relatam preocupações com algum conteúdo específico da área da Educação Física. Consideramos que essa é outra pista para a formação inicial. As pesquisas na área da formação de professores colocam a necessidade das universidades se aproximarem das escolas e fazerem uma formação como recomendada por Nóvoa (2012, p.13), que propõe uma formação de professores a partir de dentro da profissão, tencionando "a necessidade de os professores terem um lugar predominante na formação dos seus colegas".

$\mathrm{Na}$ estrutura do PRD, os referenciais teóricos para que os residentes articulassem com as práticas em serviço, aproximando-os constantemente à teoria/prática, são desenvolvidos com certa flexibilidade, sendo apresentado no formato de oficinas, palestras e minicursos desenvolvidos com temáticas referentes ao campo educacional. A não organização por disciplinas tinha o interesse de que o professor residente refletisse sua realidade e apresentasse possibilidades de solução para os problemas, e buscasse referência de forma autônoma e de seu interesse, o que nos parece relevante em se tratando de uma formação continuada.

Os sujeitos narradores da pesquisa constroem, de forma mais explicita ou não, as trocas nas distintas experiências vivenciadas e reconhecem não serem mais os mesmos de quando iniciaram o programa. Ivone afirma que participar do PRD impactou sua formação de diferentes maneiras, por meio das trocas entre ela os residentes. Essa experiência the permitiu conhecer outras realidades e aprender com elas, traçando uma diferença em seu percurso não apenas como orientadora, mas também enquanto docente, bem como destacado no trecho a seguir:

[...] então essa troca com eles foi um aprendizado para mim também, me mudou, me fez ver com outros olhos, e isso é importante. Eu falo sempre da importância dessa troca, não é se distanciar por ser uma professora supervisora, é propor trabalhar junto, eu acredito muito nessa coletividade, para mim, essa troca com eles foi significativa, abre o nosso olhar, faz a gente 
agradecer o que tem, ao invés de ficar criticando. (Narrativa da professora supervisora Ivone)

Notamos ainda que o relato da Ivone corrobora com o relato abaixo, do professor Fabiano, e ainda, com os apontamentos do Nóvoa (2012), ao trazer suas experiências atravessadas não apenas pela singularidade do percurso, mas a partir da necessidade de construir relações mais proximais, com enfoque nas trocas, diálogos e horizontalidade para que um professor esteja inserido numa formação continuada, em que toma-se como parte não apenas a sala de aula, mas toda a estrutura e ambiente ao seu redor, fazendo disso, composição de sua pratica. Ou seja, ser professor se dá em diversas esferas e diversas maneiras, sempre em acordo e colaboração uns com os outros e todos aqueles que compõem o ambiente escolar.

A construção da identidade docente se dá ao longo da vida e essa experiência de três anos me constituiu enquanto professor. A cada contato, diálogo e troca fui me enriquecendo desses outros sujeitos, desses outros olhares, dessas identidades e representações. As formas como eles colocavam seus olhares sobre o meu trabalho, pontuavam minha experiência docente, as minhas aulas. Essa troca, essa construção identitária se fez de forma processual, digamos assim, não linear e profunda de certa forma. (Narrativa do professor supervisor Fabiano)

No contexto da pesquisa em que buscamos diversas experiências de formação continuada, principalmente no início da carreira, podemos destacar que o PRD é um programa de formação continuada que promove o diálogo entre professores de educação básica de redes públicas de ensino de diferentes realidades, trazendo para a escola debates muitas vezes restritos à universidade. Além disso, segundo os supervisores, a ideia de o residente estar em contato direto com seus pares, aprendendo, observando, sugerindo e intervindo junto, permite uma nova maneira de estabelecer a formação continuada.

\section{Considerações finais}

Direcionamos nosso olhar para o PRD do Colégio Pedro II e aos professores supervisores e residentes de Educação Física por ser a área de nossa formação inicial. Buscamos em diferentes fontes de conhecimento aprofundar nossa compreensão acerca da organização, seus objetivos, métodos e como os professores participantes vivenciaram essa experiência.

Partimos, também, das formulações de Marcelo Garcia (1999), Nóvoa (1995), Tardif (2002) sobre o início e fases da carreira docente para explorar o tema proposto, e encontramos apontamentos sobre a importância deste na construção de saberes, para formação do profissional dentro da formação e da necessidade em compreender as diversas fases pelas quais os(as) professores(as) passam, independentemente do tempo de serviço, mas, também, balizados por ele.

As narrativas revelam que há de fato uma solidão, desamparo e dificuldades que atravessam o começo, tornando-o mais duro e complexo e que os professores em início de carreira precisam de uma rede de apoio, pois se sentem sozinhos, diante de um campo complexo, multifacetado e carregado de incongruências.

Apontando ainda para o fato já mencionado anteriormente, de que a escola é composta e construída não apenas pelas experiências transmitidas em sala de aula entre professores e alunos, e ainda, entre professores e seus pares, mas de que o espaço da escola é construído, sobretudo, incluindo todos que o compõem.

As narrativas revelam, também, que um dos espaços propícios para a associação do conhecimento profissional no contexto da 
sala de aula aconteceu no reconhecimento do exercício do trabalho e nas circunstâncias na qual se deparam nas distintas realidades, condições estruturais, sociais e econômicas. Essas, ao serem dialogadas com professores experientes criaram dispositivos de reflexão e análise colaborando para uma formação mais aprofundada.

O diálogo com as narrativas nos permitiu compreender que o conhecimento profissional estabelecido entre professores experientes e iniciantes reafirma que uma das dimensões relevantes para a formação de professores se faz com e na profissão. Esse é o espaço/tempo que permite emergir estratégias de superação de vários dilemas e incertezas da prática pedagógica.

Uma narrativa é sempre um processo inacabado e, ao perceber que o tema do professor iniciante, todavia, necessita de aprofundamento no campo da pesquisa de formação de professores, nos colocamos ao lado dos que desejam continuar produzindo sobre esse tema, a fim de questionarmos o cenário enfrentado pelos professores em início de carreira, e sobretudo, nos programas de inserção e apoio à docência, sabendo que trata-se de uma estrada em contínua construção e desafios que são reatualizados a cada momento e época, exigindo, assim, constante estudo.

\section{Referências}

CAVACO, Maria Helena. Oficio do professor: o tempo e as mudanças. In: NÓVOA, António (coord.). Profissão Professor. Porto/Portugal: Porto Editora, 1995. p. 155-191.

DAY, Christoper. Os professores enquanto investigadores. In: DAY, C. Desenvolvimento profissional de Professores. Lisboa: Editora Porto, 2001. p. 47-84.

FONSECA, Selva Guimarães. Ser professor no Brasil: História oral de vida. 2a ed. Campinas, SP: Papirus, (Coleção Magistério Formação e Trabalho Pedagógico). 2003
GARCIA, Carlos Marcelo. Formação de professores para uma mudança educativa. Porto: Porto Editora, 1999.

GARCIA, Carlos Marcelo; VAILLANT, Denise. Desarrollo profesional docente: cómo se aprende a enseñar? Madrid, ES: Narcea, S.A. de Ediciones. 2012.

GATTI, Bernardete Angelina. O início da carreira docente: formas de entrada, primeiras experiências profissionais e políticas educacionais. Anais... III Congreso Internacional sobre Profesorado Principiante e Inserción Profesional a la Docencia. Santiago do Chile. n.p. 2012. CD-ROM.

GIORDAN, Miriane Zanetti; HOBOLD, Márcia Souza. A escola como espaço de formação de professores iniciantes. Revista Reflexão e Ação, Santa Cruz do Sul, v. 24, n. 3, p. 7-25, Set./Dez. 2016. Disponivel em: https://online.unisc.br/seer/index.php/reflex/article/view/7534. Acesso em: 17 nov. 2018.

INFORSATO, Edson Carmo; PASSALACQUA, Flavia Graziela Moreira; LOURENÇO, Rayana Souza Longhin. Formação continuada em serviço: necessidades, possibilidades e dificuldades. In: EDUCERE XII Congresso Nacional de Educação. Paraná, 2015, p.3965439663. Disponivel em: https://educere.bruc.com.br/ arquivo/pdf2015/20525_9917.pdf. Acesso em: 15 jul. 2018.

MARIANO, André Luiz Sena. A construção do início da docência: um olhar a partir das produções da ANPEd e do ENDIPE. 142 f, 2006. Dissertação (Mestrado em Educação). Programa de Pós-graduação em Educação, Departamento de Educação, Universidade Federal de São Carlos, São Carlos, 2006.

NONO, Maévi Anabel. Professores iniciantes: o papel da escola em sua formação. Porto Alegre: Mediação, 2011.

NÓVOA, António. (Coord.). Os professores e a sua formação. 2 ed. Lisboa: Dom Quixote, 1995.

Devolver a formação de professores aos professores. Cadernos de Pesquisa em Educação PPGE/UFES. Vitória, ES. a. 9, v. 18, n. 35, p. 11-22, jan./ jun. 2012. Disponivel em: https://periodicos.ufes. br/educacao/article/view/4927/3772. Acesso em: 10 ago. 2018. 
REALI, Aline Maria Medeiros Rodrigues; TANCREDI, Regina Maria Simões Puccinelli; MIZUKAMI, Maria Graça Nicoletti. Programa de mentoria on-line: espaço para o desenvolvimento profissional de professoras iniciantes e experientes. Educação e Pesquisa. São Paulo. v. 34. n. 1, p. 77-95. jan./abr. 2008. Disponivel em: https://www.scielo.br/pdf/ep/ v34n1/a06v34n1.pdf. Acesso em: 8 ago. 2018.

TARDIF, Maurice. Saberes docentes e formação pro-

fissional. 2. ed. Petrópolis: Vozes, 2002.

Recebido em: 16/01/2020

Revisado em: 01/08/2020

Aprovado em: 09/08/2020

Fábio Jorge de Souza Molinário é professor de Educação Física formado pela Universidade Federal Fluminense (UFF). Pós-graduado em Educação Física Escolar pela UFF. Mestre em Educação por essa mesma universidade. Integrante do grupo de pesquisa Currículo, Docência e Cultura (CDC) da UFF. E-mail: fabiomolinario@gmail.com

Dinah Vasconcellos Terra é professora da Faculdade de Educação da Universidade Federal Fluminense (UFF) e do Programa de Pós-graduação em Educação da UFF. Doutora em Educação na Universidade de Barcelona - Espanha e Integrante do grupo de pesquisa Currículo, Docência e Cultura (CDC) da UFF. E-mail: dv.terra@terra.com.br 